\title{
Mapeamento da produção da cana-de-açúcar no Brasil, com ênfase no Estado do Paraná e na sua Região Noroeste ${ }^{1}$
}

\author{
Pablo Bonan², Sergio Luiz Kuhn²
}

${ }^{1}$ Aceito para publicação em $1^{\circ}$ de outubro de 2011

${ }^{2}$ Faculdade Assis Gurgacz - FAG, Curso de Agronomia. Avenida das Torres n. 500, CEP: 85.806-095, Bairro Santa Cruz, Cascavel, PR.

Palavras-chave: Açúcar, Etanol, Economia

\section{Resumo}

O cultivo da cana-de-açúcar (Saccharum officinarum L.) no Brasil é destinado, em sua maior parte, à produção de açúcar e etanol e, em menor escala, para outras finalidades, como alimentação animal e fabricação de aguardente. Devido ao setor sucroalcooleiro nacional ser referência para demais países produtores, por ter disponibilidade de terras cultiváveis para o plantio da cana, sem prejuízo dos outros alimentos, tecnologia de produção e estrutura na distribuição fez-se necessário o estudo de produção e o entendimento da cultura que se mostra tão favorável à economia nacional. A presente análise visa relatar o histórico da cana-de-açúcar, bem como, mapeamento a nível nacional, estadual e regional, produção entre açúcar e álcool, e também veículos a álcool e flex, mostrando desempenhos e variações. Para tal, como metodologia é uma pesquisa exploratória e descritiva, com dados primários, colhidos de produtores rurais e de dados secundários, levantado em bibliografias e fontes do setor. Como resultado mostra um gradativo crescimento do setor, cuja cultura em 20 anos cresceu na 


\section{B. PABLO et al.,}

ordem de $171,84 \%$, contribuindo assim com o PIB, ao que se diz respeito à agropecuária, variando entre a produção de açúcar e do etanol, em que este busca atender aos carros bicombustíveis flex, entre outros.

\section{Mapping the Production of Sugar Cane in Brazil, with Emphasis on the state of Paraná, and in the Northwest Region}

\section{Abstract}

The cultivation of sugar cane (Saccharum officinarum L.) in Brazil is intended for the most part, the production of sugar and ethanol and to a lesser extent, for other purposes such as animal feed and the manufacture of brandy. Due to the sugarcane sector is the national reference for other producing countries, to have the availability of arable land for planting sugarcane, without prejudice to other foods, production technology and structure in the distribution it was necessary to study the production and understanding of the culture that proved so favorable to the national economy. This analysis aims to report the history of cane sugar, as well as mapping the national, state and regional production between sugar and alcohol, and also alcohol and flex vehicles, and showing performance variations. To do so, as a methodology is exploratory and descriptive research, using primary data collected from farmers and secondary data, raised in bibliographies and industry sources. As a result shows a gradual growth of the sector, whose culture grew in 20 years in the order of $171.84 \%$, thus contributing to the $\mathrm{PIB}$, which relates to agriculture, ranging from the production of sugar and ethanol in this seeking to serve the flex flex-fuel cars, among others.

Key words: Sugar, Ethanol, Economy, 


\section{Introdução}

Este artigo trata da "cana de açúcar e seus derivados". Um tema e cultura relevante, em franco crescimento na produção, circulação, distribuição e no consumo interno brasileiro, bem como, nas suas exportações. O Brasil é um país continente, de vastas áreas, destaca-se pela sua produção agropecuária, cuja atividade faz uso do solo para o cultivo de plantas e a criação de animais, entre outros. No Brasil, o setor agropecuário é responsável por $27 \%$ do Produto Interno Bruto (PIB) direto, 42,5\% das exportações totais em 2009 e mais de 17 milhões de empregos. Além disso, o país é o principal fornecedor de $25 \%$ do mercado mundial de alimentos (BRASIL, 2010).

O Brasil é um dos líderes mundiais na produção e exportação de vários produtos agropecuários. Lidera o ranking na produção e exportação de café, açúcar, álcool a partir da cana-de-açúcar e o suco de laranja. Também está em primeiro lugar das vendas externas de complexo de soja (farelo; óleo e grão), carne bovina, carne de frango. É destaque na produção de milho, arroz, suínos e pescados (BRASIL, 2010).

O país vem se destacando gradativamente na sua produção primária, como em outras. No entanto, em 2008, em especial, a agropecuária brasileira cresceu $5,8 \%$ e movimentou R \$ 163,5 bilhões. Destaque para o desempenho das lavouras de trigo $(47,5 \%)$, café em grão $(25 \%)$, cana $(19,2 \%)$, milho em grão $(13,3 \%)$, arroz $(9,7 \%)$, feijão $(5,0 \%)$ e soja $(3,4 \%)$ (BRASIL, 2010).

O PIB brasileiro em 2010 teve um crescimento 7,5\% em relação ao mesmo período de 2009, sendo que a agropecuária teve crescimento $6,5 \%$, durante esta mesma época, isto se dando ao aumento de produção de várias culturas importantes da lavoura brasileira, com destaque 
B. PABLO et al.,

para a soja $(20,2 \%)$, trigo $(20,1 \%)$, café $(17,6 \%)$, milho $(9,4 \%)$, cana $(5,7 \%)$ e laranja $(4,1 \%)$ (BRASIL, 2010).

$\mathrm{O}$ desenvolvimento científico-tecnológico e a modernização da atividade rural contribuem para o bom desempenho do agronegócio brasileiro, também nas exportações e para a crescente oferta de empregos no setor. Além do solo fértil, da disponibilidade de água, da biodiversidade e da mão-deobra qualificada, o Brasil investe na produção de máquinas e implementos agrícolas e em pesquisas que garantem a qualidade da produção agropecuária (BRASIL, 2010)

A cana-de-açúcar, em especial, objeto de estudo, é um produto historicamente cultivado no território brasileiro, desde o Brasil colônia e que representa uma grande base da agricultura brasileira, vem apresentando uma acelerada expansão nos últimos anos. Inicialmente a cana-de-açúcar foi cultivada no Brasil, por mais de quatro séculos, voltada principalmente para a fabricação de açúcar, refinado, granulado, mascavo, entre outros. Com o passar dos tempos, a cana foi gradativamente também sendo utilizada como matéria-prima para a fabricação de álcool (anidro e hidratado) e outros subprodutos, como por exemplo, o bagaço de cana, a vinhaça e a levedura, entre outros. $\mathrm{O}$ álcool também é destinado, em grande parte, ao consumo nacional e esta expansão tem como ponto de apoio o aumento do consumo dos derivados da cana, especialmente do álcool combustível (SOUZA, 2009).

Deste modo, o trabalho tem como objetivo geral realizar uma análise da produção da cana-de-açúcar no Brasil, no Paraná entre 1991 a 2011.

Como objetivos específicos a pesquisa busca: levantar dados históricos de produção e cultivo da cana, seu movimento entre álcool e açúcar, a sua relação com a produção de carros flex, e também, o comportamento de produtores 


\section{B. PABLO et al.,}

rurais diante das variáveis ocorridas com a cultura no período, em estudo.

Assim justifica-se o presente estudo, por se tratar de uma cultura em crescimento na produção brasileira, estadual e local, contribuir com a renda dos produtores rurais e do país, pelos seus derivados (álcool e açúcar, entre outros), ser uma fonte alternativa renovável não poluente de energia, entre outros.

\section{Materiais e métodos}

Esta pesquisa apropriou-se na sua metodologia da forma exploratória, descritiva, com dados primários e secundários, reunindo dados quantitativos e qualitativos, cujos resultados foram apresentados na forma de tabelas e gráficos, entre outros.

Para a realização da pesquisa, efetuou-se inicialmente um estudo da cultura e dos dados históricos, utilizando-se de fontes bibliográficas, em livros, artigos e fontes oficiais, podendo assim levantar e apresentar a introdução da cana-de-açúcar no Brasil pelos portugueses, a sua evolução ao longo do tempo em produção e área cultivada, os seus derivados, bem como, o seu crescimento econômico e a sua importância na economia nacional, entre outros.

O corte do levantamento de dados, foi a partir de 1991, ano da extinção do PRÓALCOOL - Programa Nacional do Álcool, pelo governo, cujo estudo se estendeu até os dias de hoje, quanto à produção da cana-de-açúcar no Brasil, demonstrando as suas oscilações de produção, quais anos houvera ascensão e quais decréscimo na cultura. $\mathrm{O}$ referido levantamento de dados da mesma época foi no Estado do Paraná, demonstrando também a quantidade de produção em área cultivada e toneladas de cana-de-açúcar e 


\section{B. PABLO et al.,}

açúcar produzido.

Juntamente com estes levantamentos, como dados primários, foi aplicado o instrumento de pesquisa, denominado de questionário, com questões abertas e fechadas, a uma amostra de produtores rurais, no total de 10 produtores, da região Noroeste do Paraná, região que se destaca na produção da referida cultura, pois esta tem grande importância no cenário estadual, contemplando assim os municípios de Alto Piquiri, Brasilândia do Sul, Cafezal do Sul, Umuarama, e Perobal. A amostra foi escolhida de forma aleatória, de produtores dos diferentes municípios, que se disponibilizaram a responder ao questionário, cujo corte ocorreu no mês de setembro de 2011.

O intuito de levantamento de dados quanto a produção, visou assim a verificação do perfil dos produtores, bem como, a produção e derivados, envolvendo as suas terras, vínculos contratuais entre produtores rurais e as usinas, cujas áreas físicas de produção das terras agricultáveis são predominantemente arrendadas pelas usinas ou de produção própria; o tamanho da propriedade; tempo de produção em anos, a variedade da cana, entre outros.

\section{Resultados e discussões}

Histórico da Cana-de-Açúcar no Mundo e no Brasil

A cana-de-açúcar (Saccharum Officinarum L.) é uma gramínea semiperene e originária, provavelmente, da Índia (NAPP, 2008), teve um grande deslocamento historicamente, por diferentes continentes e países. Alcançou a Pérsia e dali foi levada pelos conquistadores 


\section{B. PABLO et al.,}

árabes à costa oriental do Mediterrâneo. A seguir, os árabes a introduziram na Sicília e na Península Ibérica. Em 1300, vendia-se na Bélgica o açúcar produzido na Espanha. No século $\mathrm{XV}$, a produção das várzeas irrigadas de Valência e do Algarve, sul de Portugal, era comercializada no sul da Alemanha, nos Países Baixos e na Inglaterra.

Não se conhece a data em que os portugueses introduziram a cana-de-açúcar no Brasil, sendo aproximadamente nas décadas de 1530 e 1540 que a produção se estabeleceu em bases sólidas (FAUSTO, 2004).

Pretendendo implantar na colônia um setor econômico de alta rentabilidade e lucratividade, Portugal concentrou seus esforços na lavoura de cana-de-açúcar e na instalação da indústria açucareira. Para isso, contou com a experiência acumulada desde o século XV nos Açores e na Madeira e com a procura do açúcar no mercado externo. No Brasil, a cana-de-açúcar começou a ser cultivada para fins lucrativos após o término do ciclo do pau-brasil, quando a então colônia portuguesa foi dividida em capitanias hereditárias. Além da terra abundante e ociosa, a implantação da empresa agrícola açucareira exigia muito capital. Não conseguindo reunir o suficiente entre os capitais metropolitanos e os dos colonos, o Estado procurou e encontrou nos bancos de Amsterdã os parceiros que pudessem financiar os empreendimentos coloniais. Assim, não tardou para que empresários flamengos controlassem o refino, o transporte e a distribuição do açúcar nos mercados europeus, além de participarem no trafico de escravos (DANTAS, 1989). Os grandes centros açucareiros na Colônia foram regiões próximas a úmida zona litorânea do Nordeste brasileiro, conhecida como Zona da Mata; Pernambuco e Bahia. Fatores climáticos, geográficos, políticos e econômicos explicam essa localização. As duas capitanias combinavam, na região costeira, boa qualidade de solos e um adequado 


\section{B. PABLO et al.,}

regime de chuvas. Estavam mais próximos dos centros importadores europeus e contavam com relativa facilidade de escoamento da produção, na medida em que Salvador e Recife se tornaram portos importantes.

A rápida expansão do cultivo do açúcar transformou a Zona da Mata em uma área de monocultura. $\mathrm{O}$ volume das exportações de açúcar aumentou com regularidade durante o século. $\mathrm{O}$ aumento da produção baseou-se na extensão de terra cultivada e no crescimento da população escrava mais do que em mudanças no processo de produção e aumento de produtividade. A maior parte da cana-de-açúcar era cultivada em grandes fazendas.

O setor de exportação de açúcar foi lucrativo para vários agentes econômicos: os fazendeiros e aqueles envolvidos na comercialização, financiamentos, expedição e comércio de escravos. Os comerciantes também obtiveram lucros significativos com as importações, visto que a colônia era quase que totalmente dependente de produtos estrangeiros manufaturados e mesmo de alguns alimentos importados. No inicio do século XVII, o Brasil havia se tornado o principal fornecedor de açúcar no mundo e havia superado as especiarias asiáticas como os elementos primários do comércio anglo-português e as exportações brasileiras eram igualmente conhecidos no continente europeu.

A medida que o século XVII foi chegando ao fim, a atividade exportadora começou a enfraquecer. A queda nas exportações de açúcar não ocorreu devido à falta de melhorias tecnológicas no Brasil, pois o custo do açúcar brasileiro ainda era $30 \%$ menor do que o das plantações inglesas no Caribe. A causa do declínio foi o desenvolvimento de uma crescente quantidade da oferta do produto nas colônias inglesas, holandesas e francesas, que tinham acesso preferencial aos respectivos mercados dos países de origem (BAER, 2007). 


\section{B. PABLO et al.,}

A partir de 1815, com a introdução das máquinas a vapor e a substituição da lenha pelo bagaço da cana - medida que permitiu que diversos engenhos paralisados por falta de combustível tradicional voltassem a funcionar, como também favoreceu o cultivo de cana em áreas antes destinadas à produção de lenha - surgem às usinas e com elas a necessidade de cuidados especiais com a lavoura como seleção de sementes, irrigação, processos racionais de cultura da terra, visando o melhoramento do produto (INSTITUTO DO AÇÚCAR E ÁLCOOL, 1972).

Brasil tem uma longa tradição na produção de álcool que data da década de 1920 e, durante a Segunda Guerra Mundial, o álcool era adicionado à gasolina usada em veículos leves (WILKINSON; HERRERA, 2008). Aos poucos, outros países fortaleceram sua produção e comércio de açúcar, implicando em ciclos de prosperidade e letargia da economia açucareira brasileira durante os quatro séculos seguintes. A instabilidade gerada pela dependência externa culminou, no século XX, com forte regulamentação governamental a partir da criação do Instituto do Açúcar e do Álcool (IAA), em 1933 (NADALETO, 2008). Em 1973, no período Médici, ocorreu a primeira crise internacional do petróleo, sendo consequência da chamada Guerra do Yom Kippur, movida pelos Estados árabes contra Israel. Os países árabes produtores de petróleo se articularam para reduzir a oferta do produto e provocar forte aumento dos preços. A crise afetou profundamente o Brasil, que importava mais de $80 \%$ do total do consumo, provocando desajustes na balança de pagamentos do Brasil e colocando em risco o abastecimento interno, causando insegurança e exigindo a tomada de previdências imediatas. Mas, quando o general Geisel tomou posse em março de 1974, o clima de euforia proveniente dos anos do "milagre" ainda persistia. O novo governo lançou o II Plano Nacional 


\section{B. PABLO et al.,}

de Desenvolvimento, que buscava completar o processo de substituição de importações instalado há décadas no país, não tratando de substituir a importação de bens de consumo, mas avançar no caminho da autonomia no termo dos insumos básicos e na indústria de bens de capital. A preocupação maior era o problema energético, pois propunha-se o avanço na pesquisa de petróleo, o programa nuclear, a substituição parcial da gasolina pelo álcool e a construção de hidrelétricas.

Em 1975 foi lançado o Programa Nacional do Álcool (Proálcool), primeira iniciativa mundial para a produção de energia alternativa em larga escala. A proposta do Proálcool não se restringia apenas à redução da dependência externa de combustível e economia de divisas, mas também à interiorização do desenvolvimento, evolução da tecnologia nacional e crescimento da produção nacional de bens de capital, gerando rendas e elevando o número de empregos, entre outros.

Entre os vários resultados alcançados pelo programa destacam-se: a melhoria das condições do meio-ambiente; novas variedades de cana; geração de empregos; maior oferta de mão-de-obra no campo; criação, desenvolvimento e aperfeiçoamento do veículo a álcool e a capacidade de transformar resíduos em subprodutos de alto valor econômico (ALCOPAR).

O primeiro carro a álcool produzido em série no Brasil foi o Fiat 147, sendo este, iniciado a comercialização em 1979, e tendo o estimulo da crise do petróleo para favorecer a produção, entre os anos de 1978 e 1979. O ápice do programa foi atingido entre 1985 e 1986, quando $96 \%$ da produção nacional eram de automóveis a álcool e seu declínio se iniciou em 1988, quando os preços da gasolina se estabilizaram no mercado internacional. 


\section{B. PABLO et al.,}

No ano de 1989, os usineiros começaram a pressionar o governo do presidente José Sarney, reclamando preços mais altos e o combustível passou a faltar nos postos de abastecimento, o que provocou a queda na venda de carros a álcool. Em 1990, o programa levou mais um golpe com o lançamento de carros populares com motor 1,0 que não utilizam álcool como combustível (PEREIRA, 1999). Entretanto, o início da comercialização dos veículos bicombustíveis em 2003, tirou da estagnação a fabricação de automotivos movidos a álcool e estes passaram a representar a grande maioria das vendas brasileiras. Externamente, o etanol foi ganhando mercado especialmente diante dos preços do petróleo e de seus derivados, e em menor importância, devido aos apelos ambientais crescentes calcados na perspectiva do aquecimento global e das mudanças climáticas.

Assim, depositando no álcool combustível grande esperança de lucros com exportações e difundindo uma imagem de energia limpa e renovável, além da sua alta competitividade econômica nos mercados internacionais, o Governo brasileiro tem feito sua política externa baseado em ampla propaganda ao etanol (NADALETO, 2008)

Tradicionalmente, a cana-de-açúcar era colhida manualmente, gerando uma enorme demanda por mão-deobra na longa estação da colheita, que dura de cinco a seis meses. Os períodos de colheita no Nordeste e no Centro-Sul não coincidem, permitindo que o Brasil mantenha a sua produção durante todo o ano. A maior parte da força de trabalho não é qualificada e é composta por migrantes oriundos do Nordeste do país. A mecanização foi introduzida recentemente, principalmente no Centro-Sul, onde responde atualmente por $40 \%$ da colheita. Estima-se que uma máquina substitua até cem trabalhadores. A colheita manual tem sido persistentemente criticada pelas 


\section{B. PABLO et al.,}

condições de trabalho que acarreta e por suas implicações ambientais, uma vez que exige a queima prévia da cana-deaçúcar para facilitar seu corte. (WILKINSON; HERRERA, 2008)

O setor da cana-de-açúcar brasileiro garante empregos diretos e indiretos a mais de um milhão de pessoas, sendo que as condições de trabalho e de vida têm sido continuamente denunciadas, como condições desumanas, tendo relatos de que as condições atuais são ainda mais rigorosas que no passado. Afirma-se atualmente que apenas jovens trabalhadores com até quarenta anos de idade têm condições de enfrentar o ritmo de trabalho mais intenso e mortes têm sido atribuídas à exigência de uma maior produtividade, entre outros.

Segundo ÚNICA, ocupa cerca de 7 milhões de hectares ou cerca de $2 \%$ de toda a terra arável do Brasil, que é o maior produtor mundial, seguido por Índia, Tailândia e Austrália. As regiões de cultivo são Sudeste, Centro-Oeste, Sul e Nordeste, permitindo duas safras por ano. Portanto, durante todo o ano o Brasil produz açúcar e etanol para os mercados interno e externo.

Com o fim da regulamentação governamental, iniciou-se o regime de livre mercado, sem subsídios, com os preços do açúcar e etanol passando a ser definidos conforme as oscilações de oferta e demanda. Assim, os preços da cana passaram a depender de sua qualidade e da sua participação porcentual nos produtos finais.

Para gerenciar e equilibrar produção e demandas setoriais, a iniciativa privada tem procurado criar instrumentos de mercado, como operações futuras, e desenvolver novas oportunidades para o açúcar e o etanol, por meio da queda das barreiras protecionistas e do empenho em transformar o etanol numa 'commodity' ambiental (ÚNICA, 2008). 


\section{B. PABLO et al.,}

A partir da cana-de-açúcar podem ser produzidos açúcar, álcool anidro e álcool hidratado, além de vários subprodutos, dentre os quais merecem destaque o bagaço (biomassa), a torta de filtro, as cinzas de caldeira, o carvão das chaminés, o vinhoto ou vinhaça, o mel pobre e mais recentemente, energia termo elétrica através da queima do bagaço (NAPP, 2008).

Levantamento da produção de cana-deaçúcar/açúcar/álcool no Brasil

Com a realização do levantamento de produção em toneladas foi possível verificar um aumento significativo no setor sucroalcooleiro, sendo que esta área está em ascensão. Segundo Macedo (2007), isto se deve a diversos fatores como: a introdução de variedades de cana desenvolvidas para o Brasil; o mapeamento do genoma da cana e as transformações genéticas; a otimização da vinhaça na fertiirrigação que antes não era usada; a maior tecnificação no sistema de moagem; ao aumento da produção de energia na própria indústria, sendo algumas auto suficientes; o desenvolvimento tecnológico nas áreas de produção (agrícola e industrial), sendo eles otimização no corte, carregamento e transporte da cana, mecanização da colheita, melhoria na automação industrial e gerenciamento técnico, e introdução do motor flex na indústria automobilística, entre outras.

Pode-se observar que a partir de 1991 com o desenvolvimento agrícola juntamente com as melhorias na automação industrial, que teve inicio a ascensão na produção de cana, sendo que em 10 anos teve um aumento de $33,87 \%$, e com o isto, houve aumento de $125,27 \%$ na produção do açúcar e no álcool $2,26 \%$. Isto se deve ao fato de que com o melhoramento da cana, a qual possuía maior 


\section{B. PABLO et al.,}

teor de açúcar, e juntamente com a evolução da automação industrial, foi possível melhor o resultado final, tendo assim uma maior quantidade de açúcar. Estes avanços no setor continuaram acontecendo, havendo no Brasil, um aumento proporcional entre área física (figura 1 e 2), sendo a área colhida no país de 1990 a 2008, de 4.310 .000 para 8.140.000 hectares, registrando um crescimento de aproximados $89 \%$ na área em hectares, e a produção (figura 3, 4 e 5), conforme:

\begin{tabular}{c|c}
\hline Ano & Área Colhida (ha) \\
\hline 1990 & 4310000 \\
1991 & 4120000 \\
1992 & 4070000 \\
1993 & 4270000 \\
1994 & 4210000 \\
1995 & 4200000 \\
1996 & 3860000 \\
1997 & 4340000 \\
1998 & 4570000 \\
1999 & 4830000 \\
2000 & 4860000 \\
2001 & 4970000 \\
2002 & 5100000 \\
2003 & 5370000 \\
2004 & 5630000 \\
2005 & 5760000 \\
2006 & 6190000 \\
2007 & 6710000 \\
2008 & 8140000 \\
\hline
\end{tabular}

Figura 1: fonte Ministério da Agricultura, 2008 
B. PABLO et al.,

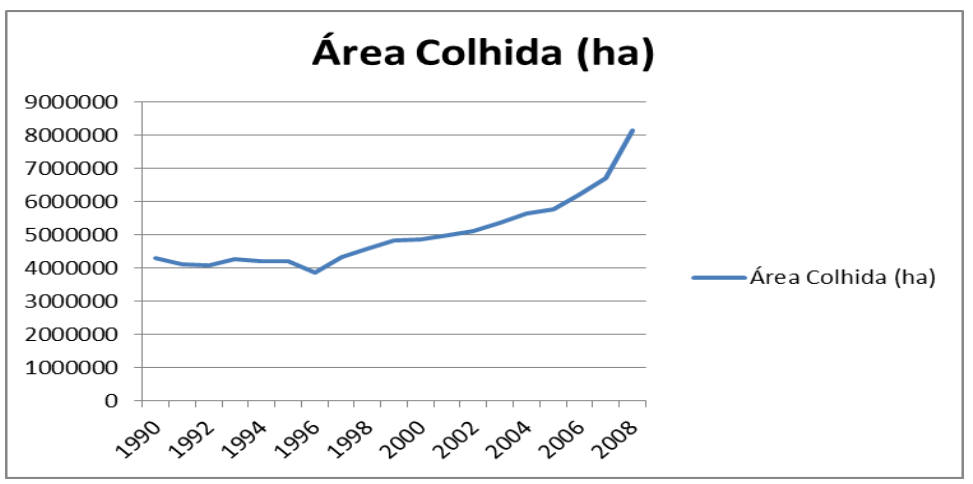

Figura 2: fonte Ministério da Agricultura, 2008.

A produção nacional de cana de açúcar na safra $10 / 11$ foi de 623.719 .902 toneladas, tendo um crescimento em 20 anos de $171,84 \%$ (figura 1, 2 e 3 ).

\begin{tabular}{l|ccc}
\hline Safra & $\begin{array}{c}\text { Produção } \\
\text { de cana-de- } \\
\text { açúcar }\end{array}$ & $\begin{array}{c}\text { Produção } \\
\text { de açúcar }\end{array}$ & $\begin{array}{c}\text { Produção } \\
\text { de álcool }\end{array}$ \\
\hline $\mathbf{9 1 / 9 2}$ & 229.441 .214 & 8.604 .321 & 12.723 .544 \\
$\mathbf{9 2 / 9 3}$ & 223.459 .875 & 9.261 .256 & 11.697 .033 \\
$\mathbf{9 3 / 9 4}$ & 218.505 .488 & 9.273 .879 & 11.285 .589 \\
$\mathbf{9 4 / 9 5}$ & 240.944 .304 & 11.726 .538 & 12.696 .780 \\
$\mathbf{9 5 / 9 6}$ & 251.491 .810 & 12.652 .995 & 12.593 .432 \\
$\mathbf{9 6 / 9 7}$ & 287.809 .852 & 13.619 .554 & 14.392 .928 \\
$\mathbf{9 7 / 9 8}$ & 304.062 .825 & 14.947 .476 & 15.437 .150 \\
$\mathbf{9 8 / 9 9}$ & 315.175 .147 & 17.978 .107 & 13.928 .246 \\
$\mathbf{9 9 / 0 0}$ & 307.156 .097 & 19.383 .099 & 13.011 .600 \\
$\mathbf{0 0 / 0 1}$ & 256.561 .588 & 16.177 .201 & 10.595 .182 \\
$\mathbf{0 1 / 0 2}$ & 293.164 .709 & 19.206 .501 & 11.520 .552 \\
$\mathbf{0 2 / 0 3}$ & 317.554 .283 & 22.419 .232 & 12.471 .478 \\
$\mathbf{0 3 / 0 4}$ & 359.127 .059 & 24.855 .564 & 14.710 .849 \\
$\mathbf{0 4 / 0 5}$ & 386.181 .958 & 25.879 .927 & 15.396308 \\
$\mathbf{0 5 / 0 6}$ & 385.202 .558 & 25.821 .464 & 15.850 .706 \\
$\mathbf{0 6 / 0 7}$ & 411.700 .276 & 28.781 .483 & 17.281 .216 \\
$\mathbf{0 7 / 0 8}$ & 496.353 .211 & 31.308 .022 & 22.468 .283 \\
\hline
\end{tabular}

Revista Brasileira de Energias Renováveis, v. 1, p. 122 - 147, 2012 
B. PABLO et al.,

\begin{tabular}{l|lll}
\hline $\mathbf{0 8 / 0 9}$ & 573.070 .559 & 31.521 .495 & 27.694 .255 \\
$\mathbf{0 9 / 1 0}$ & 603.132 .015 & 33.036 .994 & 25.742 .409 \\
$\mathbf{1 0 / 1 1}$ & 623.719 .902 & 38.174 .371 & 27.602 .429 \\
\hline
\end{tabular}

Figura 3: fonte ALCOPAR, tabela de dados referente a produção em toneladas desde a safra 91/92 até 10/11 em todo cenário nacional
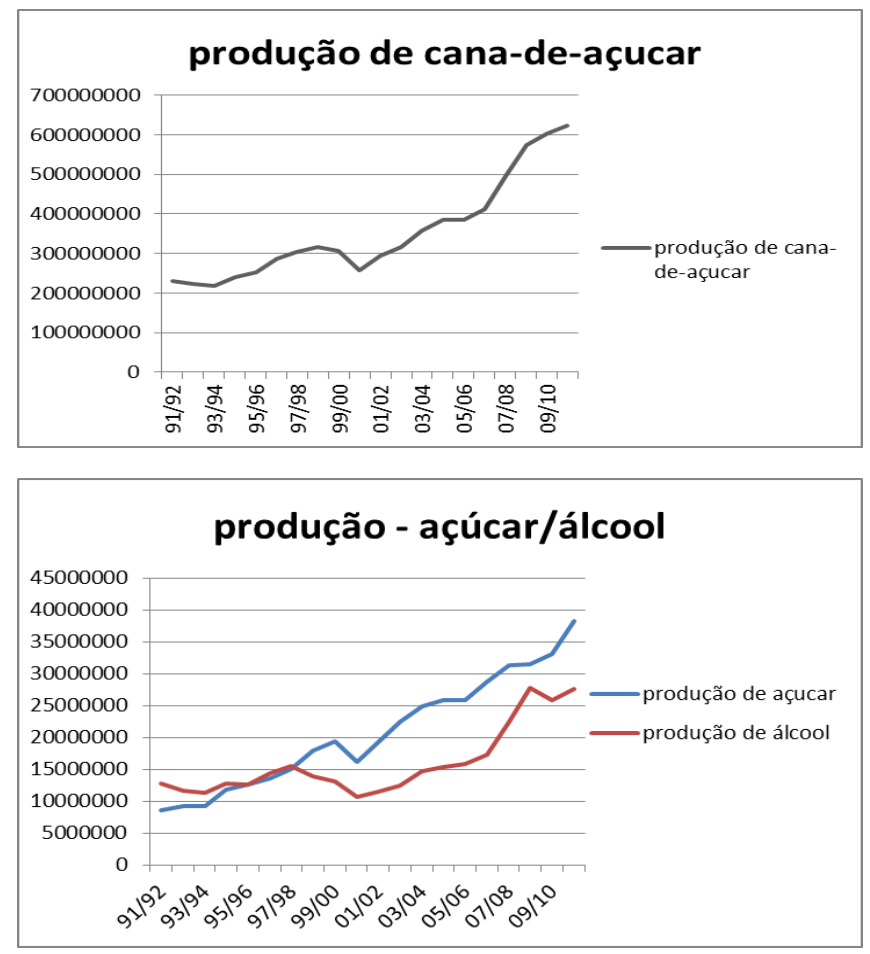

Figura 4 e 5: fonte ALCOPAR, gráfico referente a produção de cana-deaçúcar e subsequente a comparação entre produção de açúcar e álcool.

Tendo em vista que a Figura 1 demonstra a área colhida de cana-de-açúcar e a Figura 3 evidencia a produção de cana-de-açúcar, pode-se notar que a área colhida em 1991 era de 4.120 .000 e a produtividade total foi de 229.441.214, contundo 2008 a área passou para 8.140.000, tendo aumento de $97,57 \%$, com isto a produtividade subiu 


\section{B. PABLO et al.,}

para 573.070.559, tendo assim, um aumento 149,76\% na produção de cana-de-açúcar.

A área de cana-de-açúcar colhida no Brasil e destinada à atividade sucroalcooleira está estimada em 8033,6 mil hectares, distribuídas em todos estados produtores. A área colhida teve aumento de 8,40\% em relação à safra anterior (CONAB, 2011).

Juntamente com o aumento da produção da cana e seus sub-produtos e também com o incentivo do governo na produção de carros flex, pelas indústrias automobilistas no Brasil, pode-se observar que a partir de 2003, quando se deu inicio a produção de carros bicombustíveis (flex), houve em 7 anos uma alteração no mercado de venda de veículos, sendo que nos motores a álcool a diminuição na venda foi de 36.380 para 70; motores a gasolina de 1.152 .463 para 221.709; e um aumento significativo 48.178 para 2.652.298 carros bicombustíveis (figura 6 e 7)

\begin{tabular}{c|cccc}
\hline Anos & Gasolina & Álcool & Flex-fuel & Total \\
\hline $\mathbf{1 9 9 1}$ & 546.258 & 150.982 & 0 & 697.240 \\
$\mathbf{1 9 9 2}$ & 498.927 & 195.503 & 0 & 694.430 \\
$\mathbf{1 9 9 3}$ & 764.598 & 264.235 & 0 & 1.028 .833 \\
$\mathbf{1 9 9 4}$ & 1.127 .485 & 141.834 & 0 & 1.269 .319 \\
$\mathbf{1 9 9 5}$ & 1.557 .674 & 40.706 & 0 & 1.598 .380 \\
$\mathbf{1 9 9 6}$ & 1.621 .968 & 7.647 & 0 & 1.629 .615 \\
$\mathbf{1 9 9 7}$ & 1.801 .688 & 1.120 & 0 & 1.802 .808 \\
$\mathbf{1 9 9 8}$ & 1.388 .734 & 1.224 & 0 & 1.389 .958 \\
$\mathbf{1 9 9 9}$ & 1.122 .229 & 10.947 & 0 & 1.133 .176 \\
$\mathbf{2 0 0 0}$ & 1.310 .479 & 10.292 & 0 & 1.320 .771 \\
$\mathbf{2 0 0 1}$ & 1.412 .420 & 18.335 & 0 & 1.430 .755 \\
$\mathbf{2 0 0 2}$ & 1.283 .963 & 55.961 & 0 & 1.339 .924 \\
$\mathbf{2 0 0 3}$ & 1.152 .463 & 36.380 & 48.178 & 1.237 .021 \\
$\mathbf{2 0 0 4}$ & 1.077 .945 & 50.949 & 328.379 & 1.457 .273 \\
$\mathbf{2 0 0 5}$ & 697.004 & 32.357 & 812.104 & 1.541 .465 \\
$\mathbf{2 0 0 6}$ & 316.561 & 1.863 & 1.430 .334 & 1.748 .758 \\
$\mathbf{2 0 0 7}$ & 245.660 & 107 & 2.003 .090 & 2.248 .857 \\
\hline
\end{tabular}

Revista Brasileira de Energias Renováveis, v. 1, p. 122 - 147, 2012 
B. PABLO et al.,

\begin{tabular}{l|llll}
\hline $\mathbf{2 0 0 8}$ & 217.021 & 84 & 2.329 .247 & 2.546 .352 \\
$\mathbf{2 0 0 9}$ & 221.709 & 70 & 2.652 .298 & 2.874 .077 \\
\hline
\end{tabular}

Figura 6: Fonte: Associação Nacional dos Fabricantes de Veículos Automotores - Brasil / ANFAVEA. Licenciamento de automóveis e comerciais leves por tipo de combustível

1) Os dados até 2004 referem-se a vendas internas no atacado. Os dados a partir de 2004 fazem referência ao número de veículos licenciados

2) Inclui somente os veículos do Ciclo Otto (não estão contabilizados os comerciais leves movidos a diesel).

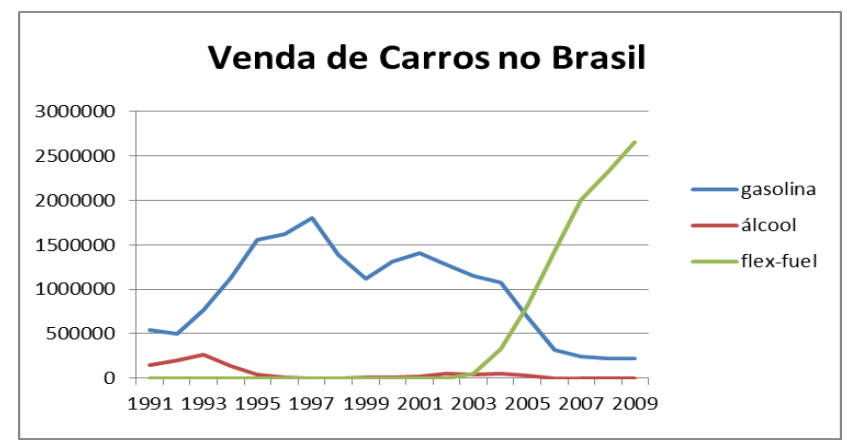

Figura 7: Fonte: Associação Nacional dos Fabricantes de Veículos Automotores - Brasil / ANFAVEA. Licenciamento de automóveis e comerciais leves por tipo de combustível

\section{Levantamento da produção de cana-de-açúcar no Paraná}

A figura 8, demonstra a participação que o Paraná tem em relação ao Brasil no que se diz respeito a produção de cana-de-açúcar em toneladas. Na safa 91/92 o Paraná obteve uma produção de 11.401.098/ton. contra 229.441.214/ton. do Brasil, tendo $5 \%$ da cadeia produtiva da cana-de-açúcar, sendo que pode-se observar um crescimento durante 7 anos (91/92 até 97/98), ficando estável por 7 anos (98/99 até 04/05) anos, tendo um decréscimo na safra 05/06, mas mesmo assim, manteve uma participação total de $6,4 \%$ na produção nacional, sendo que após isto houve um crescimento durante 2 anos (06/07 até 07/08), sucedido por uma retração, finalizando com $6,9 \%$ do cenário nacional. 
B. PABLO et al.,

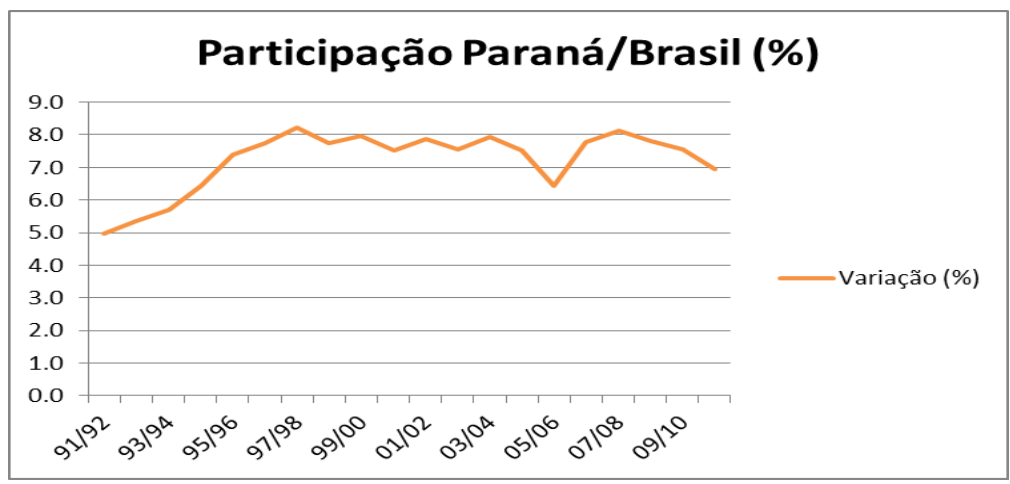

Figura 8: fonte ALCOPAR

Segundo CONAB (2011), a diminuição da produtividade na última safra está ligada a diversos fatores e o clima é o principal. A estiagem ocorrida de abril a outubro de 2010, a escassez de chuvas no mês de maio de 2011, a ocorrência de geadas em São Paulo, Mato Grosso do Sul, e Paraná e o florescimento em excesso de boa parte da lavoura, fizeram a queda da produtividade ser a maior dos últimos anos. A falta de chuvas nos períodos indicados não permitiu o pleno desenvolvimento dos canaviais e provocou o atraso no início da moagem da safra 2011/12 e o período de entre safra ficou maior.

\section{Produtores de Cana-de-Açúcar no Nordeste do Paraná}

No Noroeste existem em funcionamento 14 usinas de álcool, todas implantadas depois dos anos 1980. Em função das usinas, 190.068 hectares de terras da região são ocupados por canaviais, o que a torna responsável por $44 \%$ da produção de álcool do Estado do Paraná, conforme dados do IPARDES. Por outro lado, a produção de cana do Paraná, com a participação das lavouras do noroeste, representou $7,5 \%$ da produção nacional em 2006/07, contra 2,8\% em $1975 / 76$, época em que o café ainda era a cultura predominante. Vale destacar que, a produção de álcool 


\section{B. PABLO et al.,}

acompanha a evolução da produção de cana: correspondia a $3,6 \%$ da produção nacional em 1975/76, atingindo 7,4\% em 2006/07. Em números exatos, considerando os dados de 2006/07, o Paraná produz 32.118.523 toneladas de cana, 83.840.960 sacas de 50 quilos de açúcar e 1.333.455 metros cúbicos de álcool (SHIKIDA, 2005). Porém, o preço é o principal fator, que determina o incremento de produção ora de álcool e ou de açúcar, em função do mercado, que melhor o remunera. Assim sendo, no Estado, são os municípios produtores de cana de açúcar e as suas respectivas usinas, conforme constante no mapa do Estado do Paraná (figura 9):

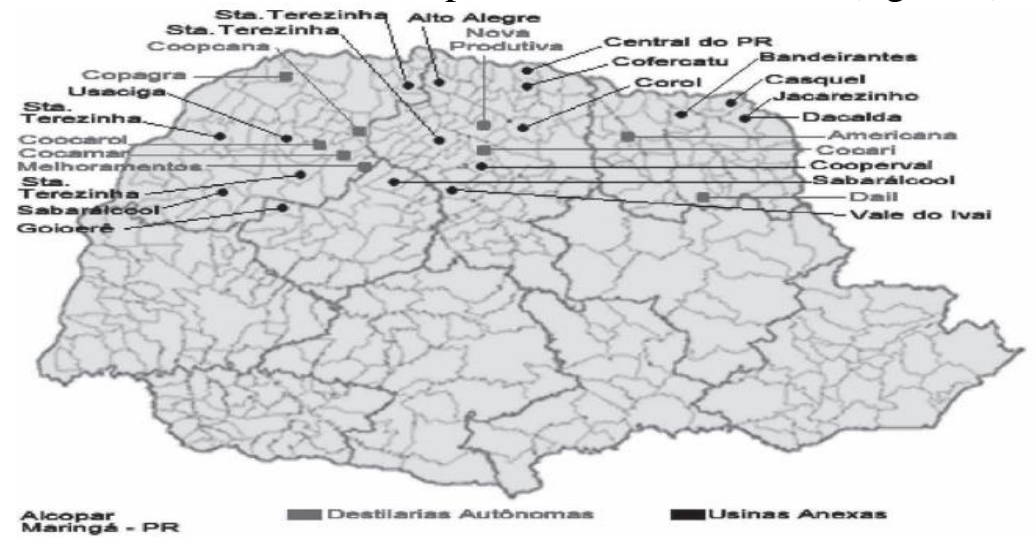

Figura 9: fonte ALCOOPAR (2011)

Devido a grande área de produção e o número de usinas de cana-de-açúcar existentes na regiao Noroeste do Paraná, foi possivel aplicar os questionários com os produtores da referida região, contemplando em especial os municipios de Alto Piquiri, Brasilândia do Sul, Cafezal do Sul, Umuarama, e Perobal. Através deste meio, possibilitou compreender que dos 10 produtores intrevistados, 100\% destes tem as suas terras arrendadas, estando na atividade em média de 12,5 anos, sendo o que trabalha a mais tempo com a cultura, a faz por mais de 20 anos e o que tem menos tempo, a faz a 3anos (figura 10). 
B. PABLO et al.,

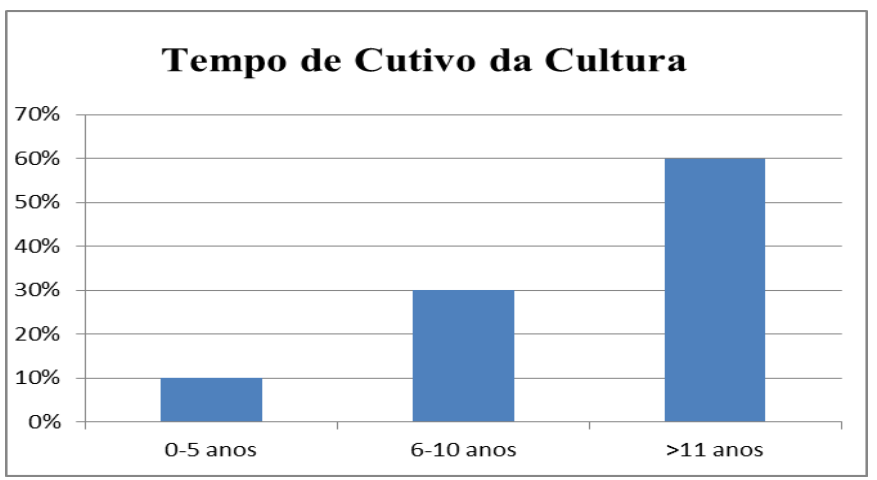

Figura 10: fonte oriunda de dados colhidos

Segundo Neves (1998), a transação de venda de cana entre produtores e Usinas é um dos pontos mais importantes e conflituosos do sistema agroindustrial da cana-de-açúcar, onde notadamente as partes não se comportam como parceiras, buscando relacionamentos estáveis e de longo prazo, com divisão de riscos e margens. O que se observa na maioria dos casos é uma visão de curtíssimo prazo, visando resultado imediato.

Existem usinas que são donas das terras, onde se planta a cana através de sua estrutura gerencial, sob o seu comando decisório, caracterizando uma integração vertical.

Existem também arrendamentos de terras de produtores rurais por Usinas, constituindo (cultivando) a cana, onde a Usina tem controle total, mas não é dona dos ativos envolvidos na produção. Quem gerencia a cultura é a Usina, cabendo ao proprietário da terra algum tipo de monitoramento da conservação do solo e da área. O arrendamento também pode ser de forma contrária, ou seja, produtor especializado produzindo em terras de Usinas, para fornecer a estas. Este arrendamento normalmente é conhecido como parceria rural, para fins fiscais. Também ocorrem arrendamentos entre produtores. 


\section{B. PABLO et al.,}

$\mathrm{Ou}$ ainda produtores especializados, que são os produtores de cana, sendo especializados na atividade de produção primária da cultura da cana, estando ligados "contratualmente" às Usinas. Já as atividades laborais que são realizadas pelos produtores rurais são as capinas manuais, aceros contra o fogo, tríplice operação e aplicação de herbicidas. A colheita e o plantio podem também ser feitas pelos produtores, ou contratadas das Usinas, o que depende do formato do vínculo contratual entre as partes.

No questionário foi abordado quanto ao tamanho das propriedades em hectares (figura 9), sendo assim, vericou-se que a maior parte dos produtores rurais possui na média, cerca de 100 há, ou seja, acima de 4 módulos fiscias, enquadrando-se entre médios e grandes produtores rurais.

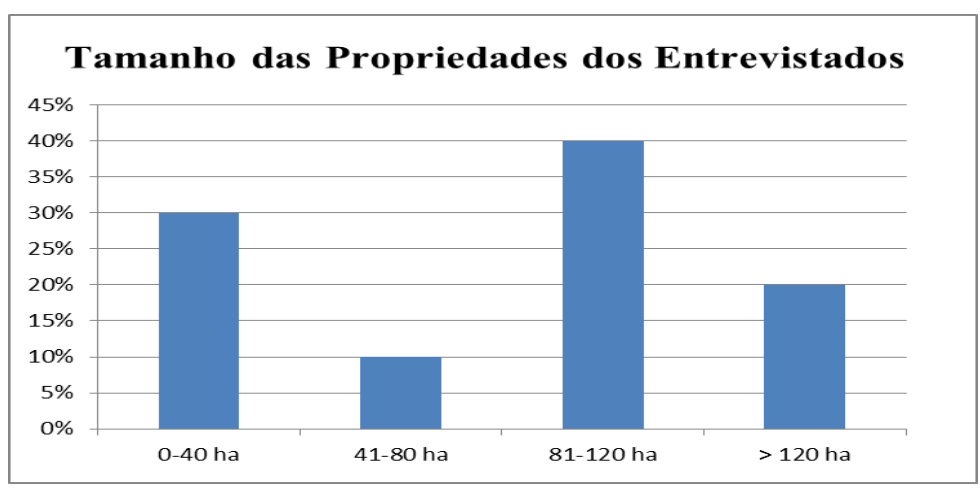

Figura 11: fonte oriunda de dados colhidos

Os produtores se mostram satisfeitos devido ao fato da cultura ser estável e ter garantia de pagamento, independente de fatores climáticos ou por questão de mercado, diferentemente se estes plantassem por conta própria alguma outra cultura, como soja ou milho, ou até mesmo extensivo de bovidos de leite ou corte ou outro. Estes produtores pretendem continuar com a área plantada, sendo que só aumentarão se comprarem mais terra, pois a grande maioria da área está destinada para a plantação da 


\section{B. PABLO et al.,}

cultura da cana. A única reclamação feita pelos produtores foi o fato de que a usina demora para fazer o pagamento de aluguel sobre a terra, porém nunca deixaram de honrar o compromisso acordado entre as partes, mediante o respectivo pagamento do mesmo.

\section{Conclusões}

Portanto, com base nas pesquisas, foi possível concluir, respondendo aos objetivos do estudo, que a agroindústria Brasileira é referência no país e também no âmbito mundial, apontando a cana em especial, recebe uma maior admiração devido à história e os benefícios trazidos ao Brasil desde a colonização até os dias de hoje, sendo que isto só foi possível perceber através de coleta de dados históricos cana-de-açúcar, podendo também demonstrar e entender todo o avanço da cana-de-açúcar no Brasil, e principalmente com relação aos seus principais subprodutos, como é o caso do açúcar e do etanol, que demonstraram um grande aumento de cultivo em área física (hectares), produção e em produtividade, principalmente por causa aos avanços genéticos, a boa adaptação da cana ao clima do país, ao melhor manejo da cultura e tecnologia para colheita e produção destes subprodutos, entre outros.

Pelos dados históricos constatou-se a alteração da produção da indústria de veículos, com a produção em massa do bicombustível (flex). Percebeu-se que as alterações nos volumes de produção entre etanol, açúcar e outros, dependem dos preços do mercado, o que faz a indústria se adequar na condição do melhor retorno econômico a atividade de produção.

Através do questionário aplicado aos produtores rurais foi possível identificar o alto grau de arrendamento de terras produtivas, mediante contratos entre proprietários de terra $\mathrm{e}$ as usinas, revelar também a situação atual dos produtores, 


\section{B. PABLO et al.,}

que se mostram satisfeitos com a cultura, provando assim que o setor canavieiro paranaense atualmente se encontra em um momento pleno, de avanços e com grandes perspectivas para o futuro, sendo que, se continuar assim cada vez mais terá relevância no cenário nacional, tornando cada vez mais o Brasil um país modelo quanto ao setor agropecuário, na produção de agroenergia alternativa, entre outros.

Diante do qual, recomenda-se ações das entidades, como: ALCOOPAR,Centros e Institutos de Pesquisa, bem como, do governo e seu órgãos, para pesquisas, fomento e apoio, na melhoria gradativa da tecnologia, na qualidade do produto, para o suprimento das necessidades da frota, dos domicílios e do consumo brasileiro, entre outros.

\section{Referências}

ALCOPAR, Associação de Produtores de Bioenergia do Estado do Paraná. Disponível em: <http://www.alcopar.org.br/> acessado em Abril, 2011

ANFAVEA, Associação Nacional dos Fabricantes de Veículos Automotores <http://www.anfavea.com.br> acessado em agosto de 2011

BAER, Werner. A economia brasileira. $2^{\text {a }}$ ed. São Paulo: Nobel, 2007

BRASIL. Setores da economia <http://www.brasil.gov.br> acessado em setembro de 2011

CONAB. Companhia Nacional de Abastecimento. < http://www.conab.gov.br/> acessado em agosto de 2011 
B. PABLO et al.,

DANTAS, José. História do brasil. $1^{\text {a }}$ ed. São Paulo: Moderna, 1989

FAUSTO, Boris. História do Brasil. $12^{\mathrm{a}}$ ed. São Paulo: Universidade de São Paulo, 2004

INSTITUTO DO AÇÚCAR E ÁLCOOL. Brasil / Açúcar. Coleção Açucareira, Rio de Janeiro, v. 8, 1972.

IPARDES. Instituto Paranaense de Desenvolvimento Econômico e Social. <www.ipardes.gov.br> acessado em julho de 2011

MACEDO, Isaias C. Situação atual e perspectivas do etanol. Estudos Avançados 21 (59), 2007

MINISTERIO DA AGRICULTURA. <http://www.agricultura.gov.br> acessado em: setembro, 2011

NADALETO, C. E. S.; WEHRMANN, M. E. S. F. O setor sucroalcooleiro moderno e suas raízes coloniais propagando-se no campo ideológico do desenvolvimento sustentável. Anais do $3^{\circ}$ seminário sobre sustentabilidade, 2008, Curitiba. FAE Centro Universitário

NAPP, A. C. T. Análise da produção e mercado do setor sucroalcooleiro brasileiro sob a ótica do impacto econômico e ambiental. Dissertação (Mestrado em Economia) Unisinos - Universidade do Vale do Rio dos Sinos. São Leopoldo, 2008. 
B. PABLO et al.,

NEVES, M.F.; WAACK, R.S.; MARINO, M.K. - Sistema Agroindustrial da Cana-de-Açúcar: Caracterização das Transações entre Empresas de Insumos, Produtores de Cana e Usinas - Anais do XXXVI Congresso da Sociedade Brasileira de Economia e Sociologia Rural - SOBER, Poços de Caldas, M.G., 1998, Vol. 01, p. 559-572.

PEREIRA, F. V. Proálcool surge com crise do petróleo. Folha de São Paulo, São Paulo, 1999. Brasil.

SHIKIDA. P.F.A. Impactos das transformações institucionais e do progresso técnico sobre os fornecedores de cana do estado do Paraná. In: Revista Ciências Empresariais. Toledo: Unipar, jan./jun. 2005

SOUZA, Adriana P. Análise econômica e emergética dos sistemas de colheita da cana de açúcar. 2009. Dissertação (Mestrado em Desenvolvimento Regional e Agronegócio) Universidade Federal do Tocantins

UNICA, União da indústria de cana-de-açúcar $<$ http://www.unica.com.br > acessado em Agosto, 2011

WILKINSON, J.; HERRERA, S.. Os agro-combustíveis no Brasil.. PDA/UFRRJ. Programa de Pós-Graduação de Ciências Sociais em Desenvolvimento, Agricultura e Sociedade - Universidade Federal Rural do Rio de Janeiro. Rio de Janeiro, 2008 